Eur. J. Clin. Chem. Clin. Biochem.

Vol. 30, 1992, pp. $473-479$

(C) 1992 Walter de Gruyter \& Co.

-Berlin · New York

\title{
Structural and Functional Characterization of Plasma Fibronectin in Patients with Essential Mixed Cryoglobulinaemia
}

\author{
By V. Toschi ${ }^{1}$, G. F. Fiorini ${ }^{2}$, Adele Motta ${ }^{1}$, C. Castelli $^{1}$, Maria Grazia Gagliano ${ }^{1}$ and Andrea Gibelli ${ }^{1}$ \\ 1 Department of Haematology and Blood Transfusion, Ospedale S. Carlo Borromeo, Milano \\ ${ }^{2}$ Division of Internal Medicine, Ospedale F. Villa, Mariano Comense, Como, Italy
}

(Received January 21/April 16, 1992)

Summary: Experimental studies suggest that plasma fibronectin may be involved in the cryoprecipitation of cryoglobulins in essential mixed cryoglobulinaemia; reduced plasma concentrations of the glycoprotein have been shown in the disease. The present work was undertaken in order to verify this latter finding and to detect a possible structural alteration of plasma fibronectin as result of enzymatic digestion of the molecule in vivo. This could, in turn, induce a decreased reactivity of the protein in immunometric assays and a reduced opsonic activity, which is normally due to the affinity of fibronectin to the C1q component of complement. Moreover, since a polymorphic variant of fibronectin has been described in plasma during experimental vascular injury and in patients with autoimmune vascular diseases, the aim of this study was also to verify the presence of a polymorphism of the glycoprotein in cryoglobulinaemic vasculitis. Twenty seven patients with essential mixed cryoglobulinaemia and 26 normal subjects were included in the study. Significantly reduced concentrations of plasma fibronectin, as assessed by ELISA, were found in patients when compared with controls $(231.7 \pm 15.3$ vs $316.1 \pm 16.6 \mathrm{mg} / 1, \mathrm{P}<0.0002)$. In contrast, when affinity-purified plasma fibronectin from 10 patients with essential mixed cryoglobulinaemia and 8 healthy subjects were analysed by western blotting, employing a panel of five monoclonal antibodies to different regions of the molecule, no differences were observed between patients and controls, suggesting integrity of the glycoprotein in the disease. Moreover, plasma fibronectin from cryoglobulinaemic patients and normal subjects bound to solid phase C1q in a dose-dependent manner with identical efficiency in the two groups, further suggesting that the molecule is functionally and structurally unaltered in the disease. The production of an abnormally glycosylated form of fibronectin in patients with essential mixed cryoglobulinaemia also seems to be excluded, as SDS-PAGE revealed no differences in electrophoretic mobility and apparent molecular weight between fibronectin from patients and controls. Taken together these data are consistent with the hypothesis that plasma fibronectin concentrations are actually reduced in essential mixed cryoglobulinaemia possibly by consumption during cryoprecipitate formation, and that a polymorphic form of the protein is not released into the circulation during cryoglobulinaemic vasculitis.

\section{Introduction}

Fibronectins are high-molecular-mass glycoproteins present in the soluble form in plasma and in insoluble form in the extracellular matrix and basement membranes (1). The fibronectin molecule is composed of multiple globular domains capable of distinct interactions with other biological structures including fibrin, heparin, plasma transglutaminase (factor XIIIa),
S. aureus, collagen, DNA, cells and fibronectin itself; consequently it plays a central role in several biologic phenomena (2-4). Experimental studies have shown that fibronectin may be involved in some immune functions. It has been demonstrated that plasma fibronectin, mainly produced by hepatocytes (5), acts as a non-specific opsonin for particulate materials and microaggregates present in the circulation by 
enhancing their clearance by the reticuloendothelial system $(6-10)$. It has also been suggested that this glycoprotein may play a role in reticuloendothelial clearance of circulating immune-complexes primarily by binding, through its collagen binding domain, to the C1q component of complement $(11-13)$.

Essential mixed cryoglobulinaemia is a disorder characterized by widespread vasculitis and multiple organ involvement mainly due to the deposition in small vessels and tissues of circulating cold-insoluble immune-complexes (cryoglobulins) composed of monoclonal IgM with rheumatoid-factor activity bound to polyclonal IgG (14-16). Experimental studies by us and others have shown that plasma fibronectin may be associated with cryoglobulins and that it may participate in cryoprecipitate formation $(17-19)$. We also recently demonstrated that immunoenzymatically measured plasma fibronectin concentrations are reduced in patients with essential mixed cryoglobulinaemia suggesting that an impairment in plasma opsonic activity may be a feature of the disease and can therefore contribute to the abnormal persistence of cold-insoluble complexes in the circulation and to tissue damage $(19,20)$. However the possibility cannot be excluded that the reduced plasma fibronectin concentrations detected in cryoglobulinaemic patients are the result of an enzymatic cleavage of the molecule in vivo with loss of fragments essential for immunologic reactivity in the ELISA assays. This hypothesis seems to be supported by the demonstration by our group of increased concentrations of plasma tissue plasminogen activator and thrombin-antithrombin III complexes in these patients as a consequence of endothelial damage (20), suggesting that the fibronectin molecule is digested by plasmin produced by activation of the fibrinolytic pathway and/or by thrombin formed during the activation of the coagulation cascade $(21-23)$.

Many reports on the molecular biology of fibronectin have demonstrated that, in different cell systems, a single fibronectin gene can give rise, by alternative splicing of the primary transcript, to several different mRNAs which in turn generate a family of different fibronectin molecules characterized by the differential expression of the number of homologous repeats within the functional domains (24-29). A fibronectin molecule containing an extra type III domain (ED1+ FN), absent in hepatocytes but present in endothelium and platelets, has been characterized (29-32), and has been detected in plasma during experimental blood vessel injury $(30,33)$ and in patients with active collagen vascular disorders (34). A polymorphism of plasma fibronectin associated to essential mixed cryoglobulinaemia has not so far been described. In the present study we measured plasma fibronectin concentrations in a larger series of patients with essential mixed cryoglobulinaemia and we used an analytical approach which employed a panel of five monoclonal antibodies to different functional domains of fibronectin molecule and the western blot technique to detect possible structural abnormalities of the glycoprotein in this condition. Plasma fibronectin binding to $\mathrm{C} 1 \mathrm{q}$ in cryoglobulinaemic patients was also investigated.

\section{Patients and Methods}

Patients

Twenty seven patients (13 males and 14 females), aged 30 to 72 years (mean 55.2) and 26 normal subjects of comparable age (35-67 years, mean 53) and sex distribution (12 males and 14 females) were included in the study. The diagnosis of essential mixed cryoglobulinaemia was made after exclusion of underlying infectious, neoplastic, and systemic disorders. Quantitation and characterization of the cryoprecipitate were carried out as previously described (35). Mean cryocrit value was 15.2 $\pm 4.3 \%$ and the cryoglobulin composition was IgG-IgMk (monoclonal rheumatoid factor) in all cases. According to clinical chemical analyses, none of the patients showed any indications of hepatic failure. Nine patients were undergoing lowdose steroid therapy (prednisone $10-20 \mathrm{mg} /$ day) at the time of the study. Some clinical and laboratory features of patients studied are shown in table 1.

\section{Plasma samples}

Fasting blood samples were drawn from patients and controls, after obtaining informed consent, into prewarmed plastic tubes containing $38 \mathrm{~g} / 1$ sodium citrate; samples were immediately centrifuged at $2400 \mathrm{~g}$ for $15 \mathrm{~min}$ at $37^{\circ} \mathrm{C}$, and the plasma was collected and immediately deep frozen until assayed, or purified by chromatography. Before use samples were thawed at $37^{\circ} \mathrm{C}$ to avoid fibrin formation.

\section{Plasma fibronectin determination}

This was performed with an enzyme-linked immunosorbent assay (ELISA) as previously described (19) which employed a goat IgG to human fibronectin (Jackson Laboratories) as first antibody (coating antibody) and a peroxidase-conjugated goat IgG to human fibronectin as second antibody. The standard curve was prepared using both commercially available purified fibronectin (Behring) and affinity-purified fibronectin prepared in our laboratory from normal human plasma (see below). Each immunoassay included patients and controls in each run. The plates were read in a multichannel photometer (Titertek Multiscan MC, Flow Laboratories) interfaced to an Apple IIe microcomputer and the results expressed in milligrams per litre. Between-day coefficient of variation was below $5 \%$ in both patients with essential mixed cryoglobulinaemia and controls.

\section{Plasma fibronectin purification}

Plasma fibronectin from 10 patients (5 men and 5 women) and 8 normal subjects ( 5 men and 3 women) was purified using gelatin affinity chromatography according to the method described by Engvall \& Rouslahti (36). To prepare the gelatin affinity columns, gelatin (type I from porcine skin, Sigma) was coupled to CNBr-activated Sepharose 4B (Pharmacia) according to the procedure provided by the manufacturer. Citrated 
Tab. 1. Some routine clinical and laboratory findings of patients with essential mixed cryoglobulinaemia. Complement levels were measured by radial immunodiffusion and values are expressed as \% of reference normal plasma. Rheumatoid factor (RF) was assessed by ELISA and values are expressed as $\mathrm{mg} / \mathrm{l}$. Cryocrit is expressed as \%. Reference values of our laboratory are $65-140 \%$ for $\mathrm{C} 3,43-156 \%$ for $\mathrm{C} 4,64-120 \%$ for $\mathrm{C} 1 \mathrm{q}$ and below $8 \mathrm{mg} / \mathrm{l}$ for rheumatoid factor.

\begin{tabular}{|c|c|c|c|c|c|c|c|c|}
\hline Patient & Age & Sex & Cryocrit & Characterization & $\mathrm{C} 3$ & $\mathrm{C} 4$ & $\mathrm{C} 1 \mathrm{q}$ & $\mathrm{RF}$ \\
\hline 1 & 71 & 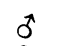 & 6.3 & IgG-IgMk & 68 & 5 & 50 & 568 \\
\hline 2 & 61 & $q$ & 4.6 & IgG-IgMk & 60 & 5 & 34 & 20 \\
\hline 3 & 50 & q & 8.8 & IgG-IgMk & 84 & 10 & 50 & 176 \\
\hline 4 & 50 & $\sigma^{2}$ & 6.5 & IgG-IgMk & 89 & 30 & 100 & - \\
\hline 5 & 46 & 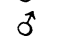 & 15.2 & IgG-IgMk & 54 & 5 & 5 & 276 \\
\hline 6 & 72 & $\overrightarrow{0}$ & 9.3 & IgG-IgMk & 32 & 5 & 0 & - \\
\hline 7 & 61 & 0 & 23.0 & IgG-IgMk & 65 & 5 & 15 & 285 \\
\hline 8 & 49 & $q$ & 11.6 & IgG-IgMk & 78 & 5 & 46 & - \\
\hline 9 & 59 & $q$ & 60.0 & IgG-IgMk & 80 & 5 & 50 & 336 \\
\hline 10 & 55 & q & 24.4 & IgG-IgMk & 58 & 5 & 24 & 768 \\
\hline
\end{tabular}

plasma $(25 \mathrm{ml})$ was applied to the column and fibronectin was then eluted with $8 \mathrm{~mol} / 1$ urea in $50 \mathrm{mmol} / 1$ Tris-buffer, $\mathrm{pH} 7.5$. The entire procedure was performed at $37^{\circ} \mathrm{C}$. Protein was determined by absorbance at $280 \mathrm{~nm}$, using as reference a standard curve prepared with commercially available purified fibronectin (Behring) at various dilutions. Plasma fibronectin recovery averaged 1.2 and $1.8 \mathrm{mg}$ of protein in patients and controls respectively. Purity of plasma fibronectin preparations was assessed by SDS-polyacrylamide gel electrophoresis (SDSPAGE) (see results).

SDS-polyacrylamide gel electrophoresis (SDSPAGE)

SDS-PAGE of purified preparations was carried out under reducing conditions using $5 \%$ acrylamide slab gels (37). The samples were reduced by incubation with $20 \mathrm{~g} / 1$ 2-mercaptoethanol at $56^{\circ} \mathrm{C}$ for 1 hour. Preliminary experiments were carried out by running purified plasma fibronectin preparations with reduced standard plasma fibronectin (Behring) $\left(M_{\mathrm{r}}\right.$ $220000)$, myosin $\left(M_{\mathrm{r}} 200000\right)$, $\beta$-galactosidase $\left(M_{\mathrm{r}} 116250\right)$, phosphorylase a $\left(M_{\mathrm{r}} 93000\right)$, human serum albumin $\left(M_{\mathrm{r}} 68000\right)$ and ovalbumin $\left(M_{\mathrm{r}} 45000\right)$ as molecular mass markers (Biorad); gel slabs were stained with Coomassie blue.

\section{Western blotting}

Proteins were transferred electrophoretically from polyacrylamide gel onto nitrocellulose paper as described by Towbin et al. (38). The blots were soaked in Tris- $\mathrm{NaCl} \mathrm{pH} 7.5+50 \mathrm{~g} / 1$ bovine serum albumin overnight at room temperature, rinsed with phosphate buffered saline, containing $10 \mathrm{~g} / \mathrm{l}$ bovine serum albumin and incubated with a $1: 1000$ dilution of the appropriate monoclonal antibody for 2 hours at $37^{\circ} \mathrm{C}$. After three extensive washes in phosphate buffered saline containing $10 \mathrm{~g} / 1$ bovine serum albumin the blots were incubated with a $1: 400$ dilution of peroxidase-conjugated anti-mouse Ig antibody (Dako) for 1 hour at $37^{\circ} \mathrm{C}$ and after three more washes the substrate $\left(500 \mathrm{~g} / 1\right.$ 4-chloro-1-naphthol in $\mathrm{H}_{2} \mathrm{O}_{2}$ ) was added and sufficient time allowed for the reaction to occur.

\section{Monoclonal antibodies}

Five commercially available monoclonal antibodies (Mallinckrodt), each recognizing different human fibronectin epitopes, were used $(39-43)$. Binding specificities and clone of origin of the antibodies employed are shown in table 2.

\section{Plasma fibronectin binding to $\mathrm{C} 1 \mathrm{q}$}

The binding of purified fibronectin from patients and controls to C1q was assessed by ELISA using a modification of the method previously described by Baatrup \& Svehag (13). Briefly, the wells of microtitre plates (Dynatech) were coated overnight with a $4 \mathrm{mg} / \mathrm{l}$ solution of $\mathrm{C1q}$ (Sigma) in phosphate buffered saline. The plates were then washed three times with phosphate buffered saline Tween and blocked with phosphate buffered saline containing $1 \mathrm{~g} / 1$ Tween and $0.5 \mathrm{~g} / 1$ human serum albumin for 2 hours at room temperature. Purified plasma fibronectin samples were serially diluted in phosphate buffered saline, and $100 \mu \mathrm{l}$ of the diluted samples and standards were added to each C1q-coated well in duplicate. The plates were then incubated for 2 hours at $37^{\circ} \mathrm{C}$. The standard fibronectin curve was obtained by using purified fibronectin from a commercial source

Tab. 2. Monoclonal antibodies employed in plasma fibronectin molecule mapping by western blotting. The specificity of the antibodies, i. e. the region of fibronectin recognized, and the clone from which the different monoclonal antibodies were isolated are reported accordingly with information specified in the data sheet provided by the manufacturer. For references see $39-43$.

\begin{tabular}{|c|c|c|c|}
\hline & $\begin{array}{l}\text { Monoclonal } \\
\text { antibody }\end{array}$ & $\begin{array}{l}\text { Clone } \\
\text { Immunoglobulin } \\
\text { class }\end{array}$ & Specificity \\
\hline $\begin{array}{l}\text { CT } \\
\text { ECS } \\
\text { NT } \\
\text { MM } \\
\text { CBP } \\
\text { CBS }\end{array}$ & $\begin{array}{l}\text { B68A11 } \\
\text { 910D18 } \\
\text { 1032B53 } \\
875 A 51 \\
784 A 2 A 6 \\
790 D 24\end{array}$ & $\begin{array}{l}\text { IgGl } \\
\text { IgG1 } \\
\text { IgM } \\
\text { IgG1 } \\
\text { IgGl } \\
\text { IgGl }\end{array}$ & $\begin{array}{l}\text { C-terminal domain } \\
\text { elastase cleavage site } \\
\text { N-terminal domain } \\
\text { central portion of fibronectin monomer } \\
M_{\mathrm{r}} 11000 \text { cell adhesive fragment } \\
\text { pepsin cleavage site at } \mathrm{N} \text {-terminal } \\
\text { of the } M_{\mathrm{r}} 11000 \text { cell adhesive fragment }\end{array}$ \\
\hline
\end{tabular}


(Behring). After three more washes $100 \mu \mathrm{l}$ of a peroxidaseconjugated goat anti-human fibronectin IgG (Jackson Laboratories) diluted $1: 400$ in phosphate buffered saline were added to each well. The plates were then incubated at $37^{\circ} \mathrm{C}$ for 1 hour and washed. Finally the substrate $\left(500 \mathrm{~g} / 1\right.$ ABTS in $\mathrm{H}_{2} \mathrm{O}_{2}$, KPL Laboratories) was added and sufficient time allowed for the reaction to occur. The plates were then read in a Titertek Multiscan MC photometer (Flow Laboratories) interfaced to an Apple IIe microcomputer.

\section{Statistical analysis}

Wilcoxon's rank sum test was applied when appropriate, using an IBM personal computer and a suitable statistical package (Epistat).

\section{Results}

The results of plasma fibronectin assay in patients with essential mixed cryoglobulinaemia and in controls are shown in figure 1. It can be seen that plasma fibronectin concentrations were significantly lower in the patients than in normal subjects $(231.7 \pm 15.3$ vs $316.1 \pm 16.6 \mathrm{mg} / 1, \mathrm{P}<0.0002)$, confirming our previous data obtained in a smaller group (20).

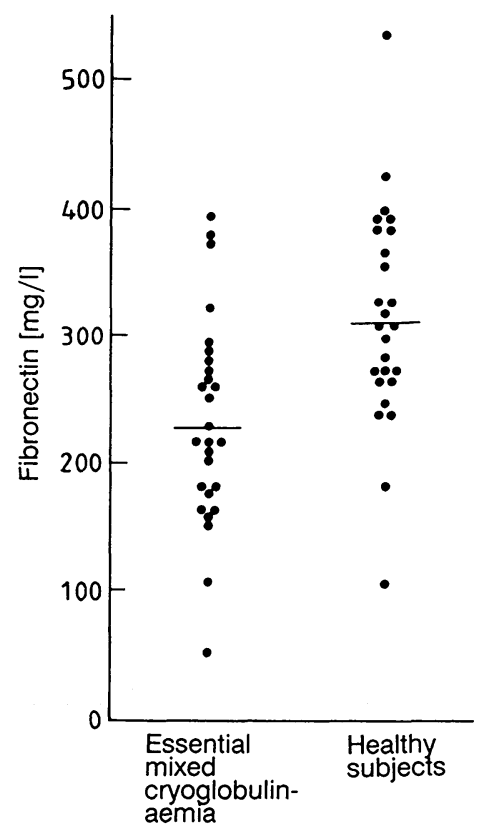

Fig. 1. Plasma fibronectin concentrations in patients with essential mixed cryoglobulinaemia (left) and in healthy subjects (right). $\mathrm{p}=0.0002$

In agreement with previously reported observations $(36,44)$, SDS-PAGE of reduced plasma fibronection from both patients and controls showed a single polypeptide band with a relative molecular mass of about $M_{\mathrm{r}} 250000$, indicating size homogeneity of the purified protein. No protein other than fibronectin was visualized by Coomassie blue staining in the purified preparations. Electrophoretic mobility of plasma fibronectin bands was identical in the two groups of subjects.
All purified plasma fibronectin samples from cryoglobulinaemic patients and control subjects stained with CBP, CBX, MM and CT monoclonal antibodies by western blot analysis (fig. 2). As can be seen, staining intensity and shape of the bands were comparable in the two groups, and no difference of reactivity was observed when commercially available plasma fibronectin (Behring) was tested. None of the plasma fibronectin preparations could be stained with the monoclonal antibody against $\mathrm{N}$-terminal region of the molecule (NT), suggesting loss of the N-terminal peptide fragment during the chromatographic procedure.

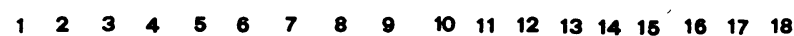

Fig. 2. Western blotting analysis of purified plasma fibronectin from normal subjects (lanes $1-4$ and 15-18) and from patients with essential mixed cryoglobulinaemia (lanes $5-14$ ) using 784A2A6 monoclonal antibody to the cell binding peptide of the fibronectin molecule.

The binding of plasma fibronectin from patients with essential mixed cryoglobulinaemia and controls to solid phase C1q is shown in figure 3. Purified fibronectin, tested at progressively halved dilutions in phosphate buffered saline at concentrations ranging from 4 to $500 \mathrm{mg} / \mathrm{l}$, was found to bind in C1q coated wells in a dose-dependent fashion, thus confirming previously reported observations $(11,13)$. As can be observed, no significant difference in binding efficiency to C1q was observed between plasma fibronectin from cryoglobulinaemic patients and that from the control group.

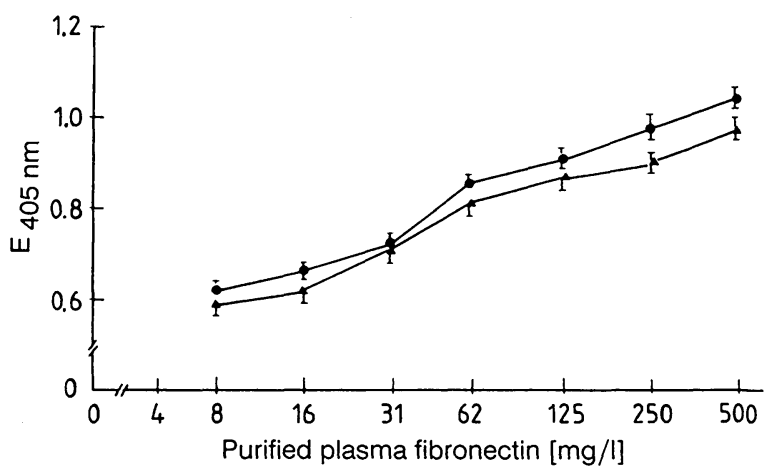

Fig. 3. Binding of purified plasma fibronectin from patients with essential mixed cryoglobulinaemia $(\boldsymbol{\Delta})$ and from healthy subjects $(\bullet)$ to solid phase C1q. Data are expressed as mean \pm SEM. 


\section{Discussion}

In the present work we confirm that plasma fibronectin is significantly decreased in patients with essential mixed cryoglobulinaemia when compared with normal controls. In contrast, when western blotting was used to map the purified molecule obtained from both groups by a panel of five monoclonal antibodies to different fibronectin epitopes, no differences were revealed between fibronectin from patients and normal subjects, suggesting that the glycoprotein structure is unaltered in the disease. We previously showed that fibronectin is constantly present in cryoprecipitate from cryoglobulinaemic patients (19), suggesting that the molecule could be actively involved in the in vivo formation of the cryoprecipitate. This, in turn, could result in the consumption of the glycoprotein, leading to a reduction of its plasma concentration. The alternative hypothesis of an enzymatic cleavage of fibronectin by plasmin and/or thrombin produced in vivo in patients with essential mixed cryoglobulinaemia with loss of immunoreactive fragments, as suggested by recent data from our group (20), seems to be excluded on the basis of the western blotting results of the present study which demonstrate that plasma fibronectin concentrations are actually reduced in the disease.

It has been shown experimentally that in different cell systems different fibronectin mRNAs originate by alternative splicing of a common precursor RNA. These, in turn, give rise to a family of fibronectin polymorphic variants differing in their primary sequences $(24-28)$. One of these polymorphic molecules containing an extra type III domain, ED1+ FN, was detected in endothelium and platelets (2932) and was shown to be released into the circulation during experimental vascular injury $(30,33)$ and to be increased in the plasma of patients with vasculitis associated with connective tissue disorders (34). In the same patients, an increased plasma concentration of total fibronectin was also reported. These data seem to contradict those found in the present work, since our experimental approach demonstrated no polymorphism of the glycoprotein in association with cryoglobulinaemic vasculitis, and significantly reduced rather than increased concentrations of total fibronectin were demonstrated in our patients. On the other hand, an impairment of the hepatic biosynthesis of plasma fibronectin, which can be advocated as a possible cause of the reduced plasma concentrations of the glycoprotein in essential mixed cryoglobulinae- mia, may be ruled out by the normality of the liver function results constantly observed in our series.

We also demonstrated that plasma fibronectin binds to solid phase $\mathrm{C1} q$ in a dose-dependent manner, thus confirming previously reported observations $(11,13)$. Recently it was also clearly shown that the glycoprotein has a strong affinity for C1q bound to fluid phase immune-complexes $(13,45)$. This interaction, mediated by the $M_{\mathrm{r}} 50000$ gelatin-binding domain of the molecule (46), may play a key role in immunecomplex clearance by the reticuloendothelial system (12), which also critically depends on the interaction of the cell-binding domain of fibronectin with macrophages (42). On the other hand, fibronectin affinity to immune complex-associated C1q also seems to be important in mediating cryoprecipitation of cryoglobulins (11). Our data demonstrate that both domains are present in fibronectin purified from patients with essential mixed cryoglobulinaemia, suggesting that enzymatic cleavage of the molecule has not occurred at these sites and that opsonic function is retained by the glycoprotein in the disease. The demonstration that plasma fibronectin from cryoglobulinaemic patients binds to $\mathrm{C} 1 \mathrm{q}$ with the same efficiency as plasma fibronectin purified from controls further supports the evidence of structural as well as functional integrity of the molecule as far as opsonic properties are concerned. However the integrity of the gelatin-binding domain of the plasma protein in essential mixed cryoglobulinaemia suggests that the molecule might also efficiently mediate cryoprecipitation of cold insoluble complexes, thereby playing a role in vascular and tissue damage.

Finally, our study also seems to exclude the possibility that an abnormally glycosylated fibronectin molecule, which has been reported in different cell systems and body fluids $(47,48)$, is produced and released in essential mixed cryoglobulinaemia; using SDS-PAGE, no differences in electrophoretic mobility or apparent molecular mass were observed between plasma fibronectin from patients and controls. However, the possibility cannot be excluded that subtle alterations are present in regions of the polypeptide chain not explored by the monoclonal antibodies employed in this study. Further work is necessary to clarify these issues.

\section{Acknowledgement}

We thank Mrs. Sonia Benuzzi for her expert technical assistance in the electrophoretic procedures. 


\section{References}

1. Hynes, R. O. \& Yamada, K. M. (1982) Fibronectins: multifunctional modular glycoproteins. J. Cell. Biol. 95, 369377.

2. Mosesson, M. W. \& Amrani, D. L. (1980) The structure and biological activities of plasma fibronectin. Blood 56 , $145-158$.

3. Rouslahti, E., Engvall, E. \& Hayman, E. G. (1981) Fibronectin: current concepts of its structure and functions. Collagen Res. 1, 95-128.

4. Mosher, D. F. (1984) Physiology of fibronectin. Ann. Rev. Med. 35, $561-575$.

5. Tamkun, J. W. \& Hynes, P. O. (1985) Plasma fibronectin is synthesized and secreted by hepatocytes. J. Biol. Chem. $258,4641-4647$.

6. Saba, T. M. \& Jaffe, E. (1980) Plasma fibronectin (opsonic glycoprotein): its synthesis by vascular endothelial cells and role in cardiopulmonary integrity after trauma as related to reticulo-endothelial function. Am. J. Med. 68, 577- 594.

7. Doran, J. E. (1983) A critical assessment of fibronectin's opsonic role for bacteria and microggregates. Vox Sang. 45, 337-348.

8. Gudewicz, P. W., Molnar, J., Lai, M. Z., Beezhold, D. W., Siefring, G. E. Jr, Credo, R. B. \& Lorand, L. (1980) Fibronectin-mediated uptake of gelatin-coated latex particles by peritoneal macrophages. J. Cell. Biol. 87, 427-433.

9. Pommier, C. G., Inada, S., Fries, L. F., Takahashi, T., Frank, M. M. \& Brown, E. J. (1983) Plasma fibronectin enhances phagocytosis of opsonized particles by human peripheral blood monocytes. J. Exp. Med. 157, 1844-1854.

10. Walton, K. W., Almond, T. J., Robinson, M. \& Scott, D L. (1984) An experimental model for the study of the opsonic activity of fibronectin in the clearance of intravascular complexes. Br. J. Exp. Pathol. 65, 191-200.

11. Kono, J., Sakurai, T., Kabashima, T., Yamane, K. \& Kashiwagi, H. (1983) Fibronectin binds to C1q: possible mechanism for their co-precipitation in cryoglobulins from patients with systemic lupus erythematosus. Clin. Exp. Immunol. 52, 305-310.

12. Sorvillo, J. M., Gigli, I. \& Pearlstein, E. (1986) The effect of fibronectin on the processing of $\mathrm{C} 1 \mathrm{q}-$ and $\mathrm{C} 3 \mathrm{~b} / \mathrm{bi}$-coated immune complexes by peripheral blood monocytes. J. Immunol. 136, 1023-1026.

13. Baatrup, G. \& Svehag, S. E. (1986) Serum and plasma fibronectin binds to complement reacted immune complexes primarily via C1q. Scand. J. Immunol. 24, 583-590.

14. Brouet, J. C., Clauvel, J. P., Danon, F., Klein, M. \& Seligman, M. (1974) Biologic and clinical significance of cryoglobulins. A report of 86 cases. Am J. Med. 57, 775788.

15. Gorevic, P. D., Kassab, H. J., Levo, Y., Kohn, R., Meltzer, M., Prose, P. \& Franklin, E. C. (1980) Mixed cryoglobulinemia: clinical aspects and long-term follow up of 40 patients. Am. J. Med. 69, 287-308.

16. Brouet, J. C. (1983) Les cryoglobulinémies. Presse Med. 12, $2991-2996$.

17. Wood, G., Rucker, M., Davis, J. W., Entwistle, R. \& Anderson, B. (1980) Interaction of plasma fibronectin with selected cryoglobulins. Clin. Exp. Immunol. 40, 358 - 364 .

18. Strevey, J., Beaulieu, A. D., Menard, C., Valet, J. P., Latulippe, L. \& Hébert, J. (1984) The role of fibronectin in the cryoprecipitation of monoclonal cryoglobulins. Clin. Exp. Immunol. 55, 340-346.

19. Toschi, V., Renoldi, P., Motta, A., Cimminiello, C., Arpaia, G. \& Fiorini, G. F. (1987) Plasma fibronectin and microvascular damage in essential mixed cryoglobulinaemia. Rheumatol. Int. 7, 213-216.

20. Toschi, V., Fiorini, G. F., Motta, A., Renoldi, P., Paracchini, M. L. \& Gibelli, A. (1991) Clinical significance of endothelial damage markers in essential mixed cryoglobulinaemia. Acta Haematol. 86, 90-94.
21. Vartio, T., Sheppa, H. \& Vaheri, A. (1981) Susceptibility to soluble and matrix fibronectin to degradation by tissue proteinase, mast cell chymase and cathepsin G. J. Biol. Chem. 256, 471-477.

22. Furie, M. B. \& Rifkin, D. B. (1980) Proteolytically derived fragments of human plasma fibronectin and their localization within the intact molecule. J. Biol. Chem. 255, $3134-3240$

23. Cotton, G. \& Brown, R. A. (1985) The effect of proteolytic degradation of plasma fibronectin on the response of functional and immunometric assays for intact fibronectin. Clin. Chim. Acta 153, 173-180.

24. Kornblihtt, A. R., Umezawa, K., Vibe-Pedersen, K. \& Baralle, F. E. (1985) Primary structure of human fibronectin: differential splicing may generate at least 10 polypeptides from a single gene. EMBO J. 4, 1755-1759.

25. Gutman, A. \& Kornblihtt, A. R. (1987) Identification of a third region of cell-specific alternative splicing in human fibronectin mRNA. Proc. Natl. Acad. Sci. USA 84, 71797182 .

26. Scwarzbauer, J. E., Patel, R. S., Fonda, D. \& Hynes, R. O. (1987) Multiple sites of alternative splicing of the rat fibronectin gene transcript. EMBO J. 6, 2573-2580.

27. Zardi, L., Carnemolla, B., Siri, A., Petersen, T. E., Paolella, G., Sebastio, G. \& Baralle, F. E. (1987) Transformed human cells produce a new fibronectin isoform by preferential alternative splicing of a previously unobserved exon. EMBO J. 6, 2337-2342.

28. Colombi, M., Barlati, S., Kornblihtt, A., Baralle, F. E. \& Vaheri, A. (1986) A family of fibronectin mRNAs in human normal and transformed cells. Biochim. Biophys. Acta 868 , $207-214$.

29. Vartio, T., Laitinen, L., Narvanen, O., Cutolo, M., Thornell, L.-E., Zardi, L. \& Virtanen, I. (1987) Differential expression of the ED sequence-containing form of cellular fibronectin in embryonic and adult human tissues. J. Cell. Sci. 88, $419-430$.

30. Peters, J. H., Ginsberg, M. H., Case, C. M. \& Cochrane, C. H. (1988) Release of soluble fibronectin containing an extra type III domain (ED1) during acute pulmonary injury mediated by oxidant or leukocytes in vivo. Am. Rev. Respir. Dis. 138, 167-174.

31. Paul, J. L., Schwarzbauer, J. E., Tamkun, J. M. \& Hynes, R. O. (1986) Cell-type-specific fibronectin subunits generated by alternative splicing. J. Biol. Chem. 261, 1225812265.

32. Peters, J. H., Sporn, L. A., Ginsberg, M. H. \& Wagner, D. D. (1990) Human endothelial cells synthesize, process, and secrete fibronectin molecules bearing an alternative spliced type III homology (ED1). Blood 75, $1801-1808$.

33. Peters, J. H., Ginsberg, M. H., Bohl, B. P., Sklar, L. A. \& Cochrane, C. G. (1986) Intravascular release of intact cellular fibronectin during oxidant-induced injury of the in vitro perfused rabbit lung. J. Clin. Invest. 78, 1596-1603.

34. Peters, J. H., Maunder, R. J., Woolf, A. D., Cochrane, C. G. \& Ginsberg, M. H. (1989) Elevated plasma levels of ED1 + ("cellular") fibronectin in patients with vascular injury. J. Lab. Clin. Med. 113, 586-597.

35. Fiorini, G. F., Bernasconi, P., Sinico, R. A., Chianese, R., Pozzi, F. \& D’Amico, G. (1986) Increased frequency of antibodies to ubiquitous viruses in essential mixed cryoglobulinemia. Clin. Exp. Immunol. 64, 65-70.

36. Engvall, E. \& Rouslahti, E. (1977) Binding of soluble form of fibroblast surface protein, fibronectin, to collagen. Int. J. Cancer 20, 1-5.

37. Laemmli, U. K. (1970) Cleavage of structural proteins during the assembly of the head of bacteriophage T4. Nature $227,680-685$. 
38. Towbin, H., Staehelin, T. \& Gordon, J. (1979) Electrophoretic transfer of proteins from polyacrylamide gels to nitrocellulose sheets: procedure and some applications. Proc. Natl. Acad. Sci. USA 76, 4350-4354.

39. Pierschbacher, M. D., Hayman, E. G. \& Rouslahti, E. (1981) Location of cell-attachment site in fibronectin with monoclonal antibodies and proteolytic fragments of the molecule. Cell 26, 259-267.

40. Smith, D. E. \& Furcht, L. T. (1982) Localization of two unique heparin binding domains of human plasma fibronectin with monoclonal antibodies. J. Biol. Chem. 257, $6518-6523$.

41. Dziadek, M., Richter, H., Schachner, M. \& Timpl, R. (1983) Monoclonal antibodies used as probes for the structural organization of the central region of fibronectin. FEBS Lett. 155, $321-325$.

42. Bohnsack, J. F., Takahashi, T. \& Brown, E. J. (1986) Interaction of culture-derived macrophages with the fibriblast-binding domain of fibronectin is a necessary but inefficient signal for fibronectin enhancement of CR1-mediated phagocytosis. J. Immunol. 136, 3793-3798.
43. Czop, J. K., Kadish, J. L., Zepf, D. M. \& Austen, K. F. (1985) Identification with monoclonal antibodies of different regions of human plasma fibronectin, including that which interacts with human monocyte fibronectin receptors. Immunology 54, 407-417.

44. Vuento, M. \& Vaheri, A. (1979) Purification of fibronectin from human plasma by affinity chromatography under non-denaturating conditions. Biochem. J. 183, 331-337.

45. Sorvillo, J. M., Gigli, I. \& Pearlstein, E. (1986) Fibronectin binding to $\mathrm{C} 1 \mathrm{q}$ associated with antigen-antibody complexes in EDTA-treated plasma. Scand. J. Immunol. 23, 153160.

46. Sorvillo, J., Gigli, I. \& Pearlstein, E. (1985) Fibronectin binding to complement subcomponent C1q. Localization of their respective binding sites. Biochem. J. 226, 207-215.

47. Rouslahti, E., Engvall, E., Hayman, E. G. \& Spiro, R. G. (1981) Comparative studies on amniotic and plasma fibronectins. Biochem. J. 193, 295-299.

48. Jones, G. E., Arumugham, R. G. \& Tanzer, M. L. (1986) Fibronectin glycosylation modulates fibroblast adhesion and spreading. J. Cell. Biol. 103, 1663-1670.

\author{
Dr. Vincenzo Toschi MD \\ Dipartimento Trasfusionale e di Ematologia \\ Ospedale S. Carlo Borromeo \\ Via Pio II, 3 \\ I-20153 Milano
}


